\title{
The effects of food restriction and exercise on site-specific differences in adipocyte volume and adipose tissue cellularity in the guinea-pig
}

\author{
2. Intermuscular sites
}

\author{
BY CAROLINE M. POND, CHRISTINE A. MATTACKS AND \\ DAWN SADLER \\ Department of Biology, The Open University, Walton Hall, Milton Keynes MK7 6AA
}

\section{(Received 14 June 1983 - Accepted 13 December 1983)}

1. Two intermuscular adipose depots, the popliteal mass (POP) and the fat under the gluteus superficialis muscle (GLS) were studied in guinea-pigs maintained under three different regimes of diet and exercise.

2. Eleven different sites in POP and four sites in GLS were defined using associated muscle and fascia as 'landmarks'. Samples of twenty to twenty-five adipocytes from each site were removed and their mean volume measured; a consistent pattern of distribution of larger and smaller adipocytes within POP and GLS was found in all animals.

3. The correlation between the volume of adipocytes from sites between the same pairs of muscles was substantially greater than the correlation between the volume of adipocytes from comparable sites between different muscles, whether the sites were within the same fat mass (POP) or in different fat masses (POP and GLS).

4. The volume of adipocytes from the edge of the fat mass correlated more closely with those from the edge of the same or a synergistic muscle than with the volume of cells from the centre sites or edge sites from an interface with another muscle. These effects were most pronounced in exercised animals and weak or insignificant in sedentary ad lib.-fed animals.

5. The volume of adipocytes from edge sites correlated with the gross weight of the adjacent muscles in exercised animals only.

6. It is concluded that muscle activity has a local effect on the volume of adjacent adipocytes. It is suggested that the mechanism involved is mechanical rather than biochemical.

The most important factor determining the proportion of adipose tissue in the body is the relationship between energy intake and energy expenditure (Garrow, 1978). Activity of skeletal muscles is a major form of energy expenditure and the one most amenable to experimental manipulation. In the many demonstrations of the role of exercise in determining adipocyte volume and adipocyte metabolism, it is usually assumed that increased energy expenditure gives rise to more lipolysis in all adipocytes, regardless of the anatomical location of the cells (Kirtland \& Gurr, 1979; Sjöström, 1980). However, changes in diet and exercise regimen also cause hypertrophy or atrophy of certain muscle fibres (Edgerton, 1978; Goss, 1978), often giving rise to significant changes in the shape and size of the whole muscle. Since a substantial proportion of the total adipose complement of large mammals is located within or between muscles (Callow, 1950; Moody \& Cassens, 1968; Butler-Hogg \& Wood, 1982), we decided to investigate the possibility that local interaction between muscle and adjacent adipose tissue was playing a part in the determination of adipocyte volume, quite apart from the effect that muscle activity may have on the animal's energy budget as a whole.

Guinea-pigs were chosen for the present study because they have adipocytes of a wide range of volumes, including some exceptionally large cells in moderately obese specimens (Kirtland \& Gurr, 1979; Pond, 1984), and because this species is naturally less inclined to jump or climb than most other laboratory rodents or lagomorphs. Their normal locomotion is a trot or a gallop, movements which do not involve extensive stretching or twisting of the limbs. 


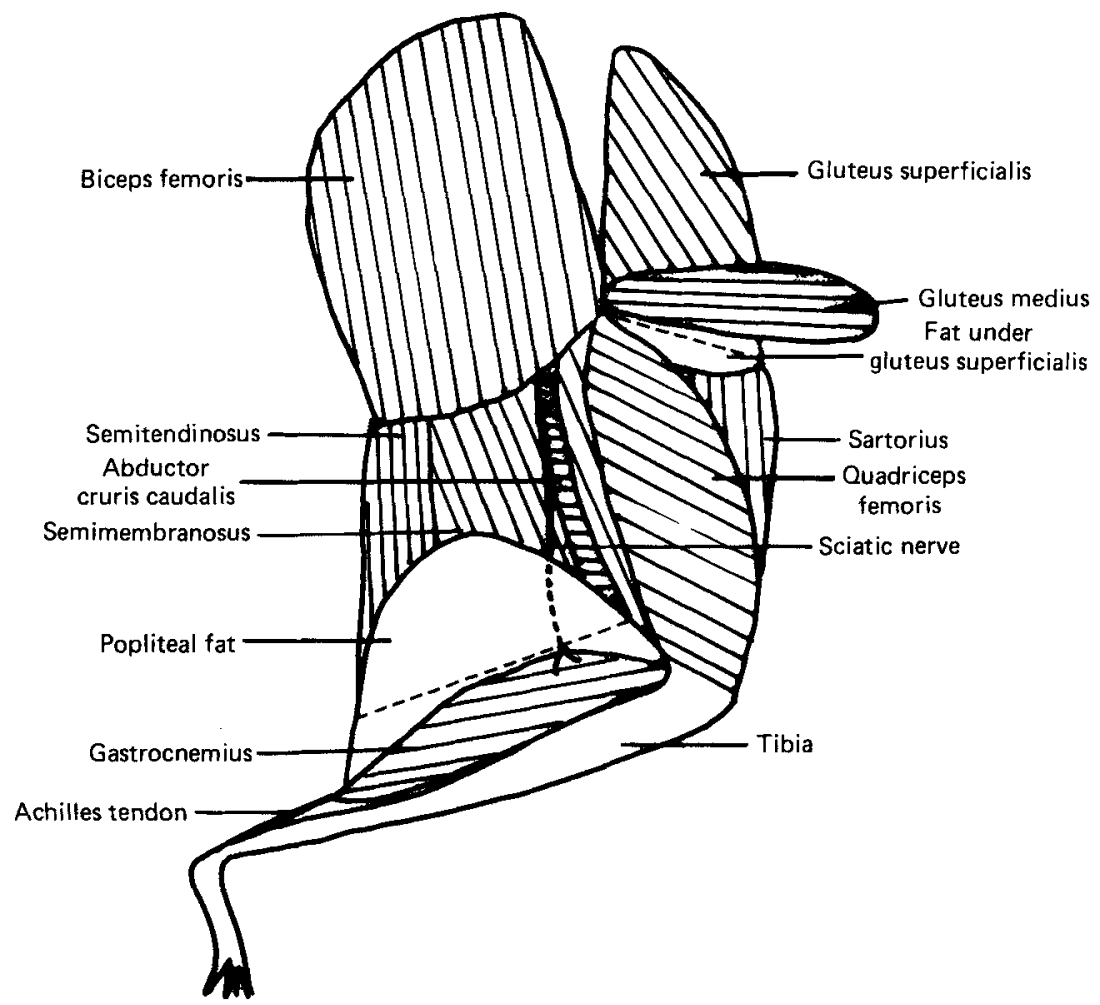

Fig. 1. Dissection of the right leg of a guinea-pig to show the anatomical relations of the two adipose masses studied. (---), Planes of section of the tissue slice from which adipocyte samples were taken.

\section{MATERIALS AND METHODS}

Details of the animals and experimental procedure have been described in full in the preceding paper (Pond et al. 1984). The present study and the work reported in the previous paper were obtained from the same group of animals. Group 1 ( $n$ 18, nine males, nine females) were confined in standard laboratory guinea-pig cages and fed ad lib. on breeding-grade ginea-pig chow throughout life. Group 2 ( $n$ 16, eight males, eight females) were kept under the same conditions as those of group 1. Beginning at the edge of about 15 weeks, they were given restricted quantities of a less-rich diet, and remained in the same cages. Group 3 ( $n 23$, ten males, thirteen females) were fed $a d$ lib. throughout life on the same diet as group 1, but transferred at the age of 15 weeks to a large outdoor pen.

Two intermuscular sites in the hind-limb were chosen for intensive study. They were the popliteal (POP) fat mass between the major flexor muscles of the knee, and the fat mass medial to the gluteus superficialis muscle (GLS). The anatomical relations of these fat masses are shown in Fig. 1. The muscles and intermuscular fat of the left leg were separated at the complete dissection, $24 \mathrm{~h}$ after death, and weighed individually. The adipose masses of the right leg were analysed in detail: for POP, the biceps femoris and abductor cruris caudalis muscles and POP fat were dissected as a single piece of tissue and frozen at $-15^{\circ}$. The frozen, unfixed specimen was then cut horizontally with a razor blade to form a thick section through the widest part of the POP fat mass. The section so formed was about $0.5 \mathrm{~mm}$ thick; it was thus about five adipocytes thick (approximate adipocyte diameter 


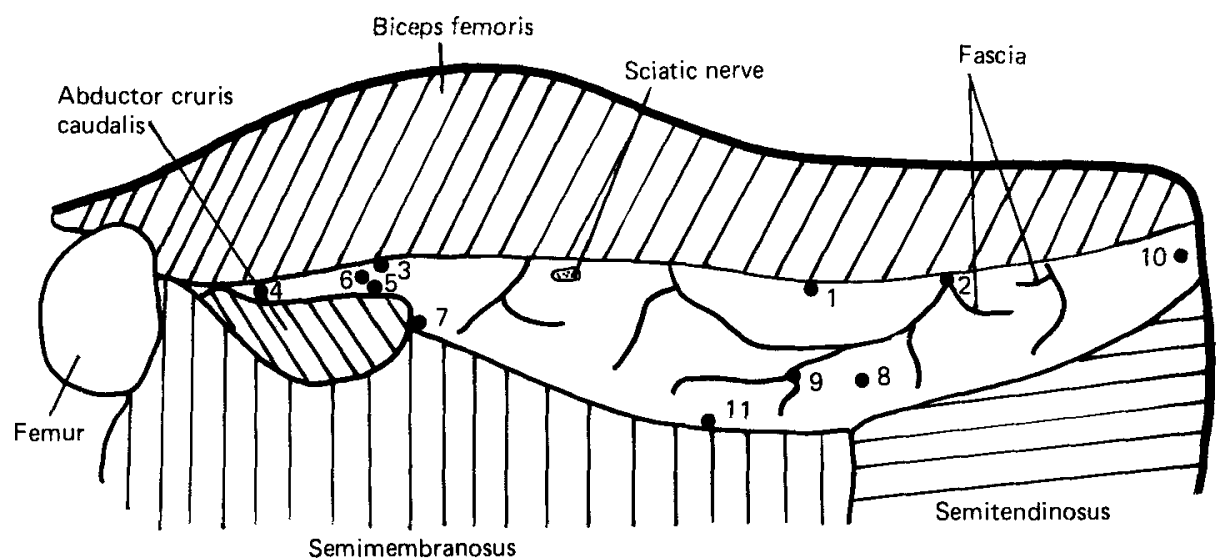

Fig. 2. Diagram of the tissue slice from the popliteal (POP) fat mass to show the position of the eleven sample sites.

90-130 $\mu \mathrm{m}$ ) in the POP region. The tissue slice was examined and eleven samples of twenty to twenty-five adipocytes were removed from each site shown in Fig. 2 . In the thin animals, this number of adipocytes was the largest number which could be reliably obtained from the narrow region shown as sites 3-6 on Fig. 2. Since the tissue slice was about five cells thick, the sample removed was approximately spherical; larger samples would have required that a 'sheet' of cells be studied, or that thicker sections be made. Duplicate measurements of the sites for which there were plenty of cells (sites 1,2,8 and 9) showed that the number chosen was sufficient to give accurate, reproducible results.

Site nos. 1 and 8 differed from site nos. 2 and 9 in that the latter were defined as being near to a knot of fascia or blood vessel, while the former were away from all visible connective tissue. The dimensions of both the fat and the muscle varied between treatment groups; the width of the POP fat was $2 \cdot 5-10 \mathrm{~mm}$ at the widest point (site nos. 1 and 2) and $0 \cdot 3-3 \cdot 0 \mathrm{~mm}$ at site nos. 3-6. The abductor cruris caudalis muscle is believed to be a synergist of the biceps femoris muscle during most movements, including locomotion (Miller et al. 1964); the other muscles surrounding the POP fat also contribute to walking and running but are not exact synergists of the biceps femoris for all movements.

The GLS fat mass of the right leg was dissected together with the GLS muscle, and was frozen and sectioned in the same way as for the analysis of POP. The GLS fat and associated muscles of the left leg were separated and weighed. Four samples were taken from the tissue slice formed from the right leg tissues: GLS site 1 was in the middle of the widest part of the fat mass ( $1-3 \mathrm{~mm}$ wide at this point), GLS site 2 was close to GLS muscle, opposite the widest part of the fat mass. GLS site 3 was from the narrow region of the fat, nearest to the insertion of the quadriceps muscles at the upper end of the femur. GLS 4 was from a nook or knot of fascia close to the edge of the inner surface of the GLS muscle.

The following muscles of the left leg were also dissected out and weighed individually: gastrocnemius, semitendinosus, semimembranosus, biceps femoris plus abductor cruris caudalis, quadriceps femoris and GLS. These hind-limb muscles were taken as representative of the whole muscle mass of the body, and their weight was used as an indicator of whether muscular wasting or hypertrophy had taken place. The adipocyte samples were measured and the mean adipcoyte volume was calculated as described previously (Pond et al. 1984). 
Table 1. Gross weight of popliteal (POP) fat mass and adjacent muscles, and number of adipocytes in POP for male and female guinea-pigs in the three treatment groups

\begin{tabular}{|c|c|c|c|c|c|c|c|}
\hline \multirow[t]{2}{*}{$\begin{array}{l}\text { Group... } \\
\text { Treatment... }\end{array}$} & & \multicolumn{2}{|c|}{$\begin{array}{c}1(n \text { 18) } \\
\text { Sedentary, } \\
\text { ad lib.-fed }\end{array}$} & \multicolumn{2}{|c|}{$\begin{array}{c}2(n 16) \\
\text { Sedentary, } \\
\text { restricted-diet }\end{array}$} & \multicolumn{2}{|c|}{$\begin{array}{c}3 \text { (n 23) } \\
\text { Exercising, } \\
\text { ad lib.-fed }\end{array}$} \\
\hline & & Mean & $\mathrm{SD}$ & Mean & SD & Mean & SD \\
\hline POP fat mass wt (g): & $\begin{array}{l}\delta \\
q \\
\text { All }\end{array}$ & $\begin{array}{l}1 \cdot 37 \\
1 \cdot 45 \\
1 \cdot 30\end{array}$ & $\begin{array}{l}0.52 \\
0.39 \\
0.38\end{array}$ & $\begin{array}{l}0.41 \\
0.50 \\
0.46\end{array}$ & $\begin{array}{l}0 \cdot 13 \\
0 \cdot 24 \\
0 \cdot 19\end{array}$ & $\begin{array}{l}0.74 \\
1.00 \\
0.89\end{array}$ & $\begin{array}{l}0 \cdot 34 \\
0 \cdot 32 \\
0 \cdot 35\end{array}$ \\
\hline POP adipocyte no. $\left(\times 10^{4}\right)$ : & $\begin{array}{l}0 \\
0 \\
\text { All }\end{array}$ & $\begin{array}{l}78 \cdot 4 \\
72 \cdot 7 \\
75 \cdot 6\end{array}$ & $\begin{array}{l}28 \cdot 5 \\
15 \cdot 0 \\
23 \cdot 7\end{array}$ & $\begin{array}{l}54 \cdot 6 \\
46 \cdot 3 \\
50 \cdot 4\end{array}$ & $\begin{array}{l}21 \cdot 0 \\
14 \cdot 0 \\
17 \cdot 7\end{array}$ & $\begin{array}{l}81 \cdot 4 \\
70 \cdot 5 \\
75 \cdot 2\end{array}$ & $\begin{array}{l}35 \cdot 1 \\
27 \cdot 2 \\
30 \cdot 9\end{array}$ \\
\hline Biceps femoris muscle wt $(\mathrm{g})$ : & $\begin{array}{l}\hbar \\
0 \\
\text { All }\end{array}$ & $\begin{array}{l}5 \cdot 61 \\
4 \cdot 81 \\
5 \cdot 21\end{array}$ & $\begin{array}{l}1 \cdot 11 \\
0 \cdot 78 \\
1 \cdot 01\end{array}$ & $\begin{array}{l}4 \cdot 72 \\
4 \cdot 11 \\
4 \cdot 41\end{array}$ & $\begin{array}{l}0.63 \\
0.62 \\
0.68\end{array}$ & $\begin{array}{l}5 \cdot 48 \\
4 \cdot 11 \\
4 \cdot 70\end{array}$ & $\begin{array}{l}1.08 \\
0.58 \\
1.07\end{array}$ \\
\hline Total wt hind-leg muscles $(\mathrm{g})$ : & $\begin{array}{l}\delta \\
q \\
\text { All }\end{array}$ & $\begin{array}{l}38 \cdot 2 \\
33 \cdot 7 \\
36 \cdot 0\end{array}$ & $\begin{array}{l}7 \cdot 30 \\
4 \cdot 32 \\
6 \cdot 26\end{array}$ & $\begin{array}{l}31 \cdot 8 \\
29 \cdot 6 \\
28 \cdot 9\end{array}$ & $\begin{array}{l}5 \cdot 02 \\
2 \cdot 52 \\
8 \cdot 56\end{array}$ & $\begin{array}{l}37 \cdot 4 \\
29 \cdot 6 \\
33 \cdot 0\end{array}$ & $\begin{array}{l}5 \cdot 27 \\
4 \cdot 55 \\
6 \cdot 19\end{array}$ \\
\hline
\end{tabular}

\section{RESULTS}

Table 1 shows some values for the POP fat mass and associated muscles for both sexes in the three treatment groups. Group 2 animals had $50 \%$ fewer adipocytes in this depot than either of the two ad lib.-fed groups, a highly-significant difference (Student's $t$ test, $t 3.54$, $P<0.01$ ). The number of adipocytes in POP is thus affected by the treatments in much the same way as the other adipose depots were affected (see Pond et al. 1984, Table 4). The weight of the lean tissue in the hind-limb was not significantly different in groups 2 and 3 (Student's $t$ test, $t 1.629, P>0.05$ ), indicating that there had not been substantial muscular wasting in the group 2 animals. Group 1 animals had substantially more fat and lean tissue, as would be expected since they were, over-all, larger than members of groups 2 and 3 (see Pond et al. 1984, Table 1). The small differences between the sexes were in keeping with the slightly larger body mass of the males and slightly greater fatness in the females, described by Pond et al. (1984). These results indicated that the POP fat mass took up and released storage lipids in the same way as other adipose depots elsewhere in the body.

The mean adipocyte volume of each of the eleven POP sites and four GLS sites from animals in the three treatment groups are listed in Table 2. The adipocytes from sites near fascia (POP sites 2 and 9) were significantly smaller than those from comparable sites away from fascia (POP sites 1 and 8 ) in the group 1 animals (Student's $t$ test, $t 2.07$ for POP sites 1 and $2, t 2.30$ for POP sites 8 and $9, P<0.05$ in both cases). The corresponding values for the other two groups showed similar trends, none of which was significant at $P<0.05$. The adipocytes at POP sites 8 and 10 were always among the largest of all adipocytes in the body. The values in Table 2 can be compared to those in Table 1 and Fig. 1 of Pond et al. (1984) for the mean cell size (MEANCS) of adipocytes in sites elsewhere in the body (for details, see p. 417 of Pond et al. (1984)); the MEANCS of adipocytes in POP site 10 was $43 \%$ greater than the corresponding MEANCS in group 1 animals, $21 \%$ greater than in group 2 and $67 \%$ greater than in group 3 . The maximum recorded mean volume of a sample of twenty-five adipocytes from POP site 10 was $3.13 \mathrm{nl}$, obtained in a group 3 animal.

Table 3 shows values for correlation coefficients and slopes calculated for the equations 
Table 2. Values for adipocyte mean cell size $(n l)$ in the eleven sites in the popliteal fat mass $(P O P)$ and the fat mass medial to the gluteus superficialis muscle $(G L S)$ in the three treatment groups

\begin{tabular}{|c|c|c|c|c|c|c|}
\hline \multirow{2}{*}{$\begin{array}{l}\text { Group... } \\
\text { Treatment... } \\
\text { Sample } \\
\text { site no. }\end{array}$} & \multicolumn{2}{|c|}{$\begin{array}{c}1(n \text { 18) } \\
\text { Sedentary, } \\
\text { ad lib.-fed }\end{array}$} & \multicolumn{2}{|c|}{$\begin{array}{c}2\left(\begin{array}{ll}n & 16) \\
\text { Sedentary, } \\
\text { restricted-diet }\end{array}\right.\end{array}$} & \multicolumn{2}{|c|}{$\begin{array}{l}3\left(\begin{array}{ll}n & 23) \\
\text { Exercising, } & \\
\text { ad lib.-fed }\end{array}\right.\end{array}$} \\
\hline & Mean & SD & Mean & SD & Mean & SD \\
\hline \multicolumn{7}{|l|}{ POP } \\
\hline 1 & $2 \cdot 115$ & 0.576 & 1.071 & 0.495 & 1.327 & 0.414 \\
\hline 2 & 1.770 & 0.410 & 0.926 & 0.508 & 1.169 & 0.346 \\
\hline 3 & 1.554 & 0.375 & 0.900 & 0.523 & 0.957 & 0.362 \\
\hline 4 & $1 \cdot 344$ & 0.326 & 0.768 & 0.523 & 0.975 & 0.357 \\
\hline 5 & 1.542 & 0.350 & 0.826 & 0.498 & 0.963 & 0.344 \\
\hline 6 & 1.654 & 0.442 & 0.952 & 0.535 & $1 \cdot 109$ & 0.375 \\
\hline 7 & 1.650 & 0.398 & 0.948 & 0.524 & 1.077 & 0.342 \\
\hline 8 & 2.209 & 0.490 & $1 \cdot 174$ & 0.535 & 1.526 & 0.499 \\
\hline 9 & 1.867 & 0.398 & 1.085 & 0.507 & 1.261 & 0.384 \\
\hline 10 & $2 \cdot 304$ & 0.383 & $1 \cdot 150$ & 0.512 & 1.730 & 0.646 \\
\hline 11 & $1 \cdot 324$ & 0.572 & 0.751 & $0 \cdot 310$ & 1.089 & 0.379 \\
\hline \multicolumn{7}{|l|}{ GLS } \\
\hline 1 & 1.999 & 0.473 & 1.038 & 0.491 & $1 \cdot 283$ & 0.326 \\
\hline 2 & 1.882 & 0.570 & 0.982 & 0.464 & $1 \cdot 110$ & $0 \cdot 268$ \\
\hline 3 & 1.850 & 0.423 & $1 \cdot 110$ & 0.634 & $1 \cdot 169$ & 0.359 \\
\hline 4 & 1.683 & 0.568 & 0.960 & 0.510 & $1 \cdot 128$ & $0 \cdot 284$ \\
\hline
\end{tabular}

relating the volumes of adipocytes from the middle of the popliteal fat mass. There was no difference between treatment groups in the relationship between the volume of adipocytes situated between the same muscles. However, when cells in sites between different muscles were compared, the correlation coefficients for group 1 animals were significantly $(P<0.05)$ lower than the corresponding values for the other two treatment groups. The slopes of the equations relating samples from sites between different muscles were also significantly lower for the group 3 values than for the group 2 values (Student's $t$ test using SE of slope, $t 4.53-2.62, P<0.02$ in all four cases) These findings indicated that the volumes of adipocytes from different sites within POP became coordinated in restricted-diet and exercised animals, but not in sedentary, ad lib.-fed animals. Exercise gave rise to a change in slope of the equation relating values of sites between different muscles. When samples from between the same muscles were compared, exercise increased the correlation between them without altering the slope of the equation relating the two measurements.

There was also an effect of exercise on the relationship between the volumes of adipocytes at the edge of the popliteal fat mass. These findings are shown in Table 4. In the two sedentary groups (groups 1 and 2), samples from the edge of the same muscle, or from the edges of two synergistic muscles (biceps femoris and abductor cruris caudalis) correlated very closely. The differences between the correlation coefficients in the three treatment groups were significant at $P<0.05$ for three of the four pairs of edge sites, but not significant for any of the three edge and centre comparisons. There was no significant difference in the slopes of any of the linear regression equations relating the volume of adipocytes from the pairs of sites studied in Table 4, so these values have been omitted from Table 4. In interpreting these findings, it is important to emphasize that the actual distance on the tissue slice between the pairs of edge sites was at least as great as that between edge and centre sites, particularly in the case of the thinner specimens in groups 2 and 3.

The relationship between volumes of adipocytes in the POP fat mass and the comparable 
Table 3. Values for correlation coefficient and slope for equations relating volumes of adipocytes from sites in the centre of the popliteal fat mass for guinea-pigs in the three treatment groups

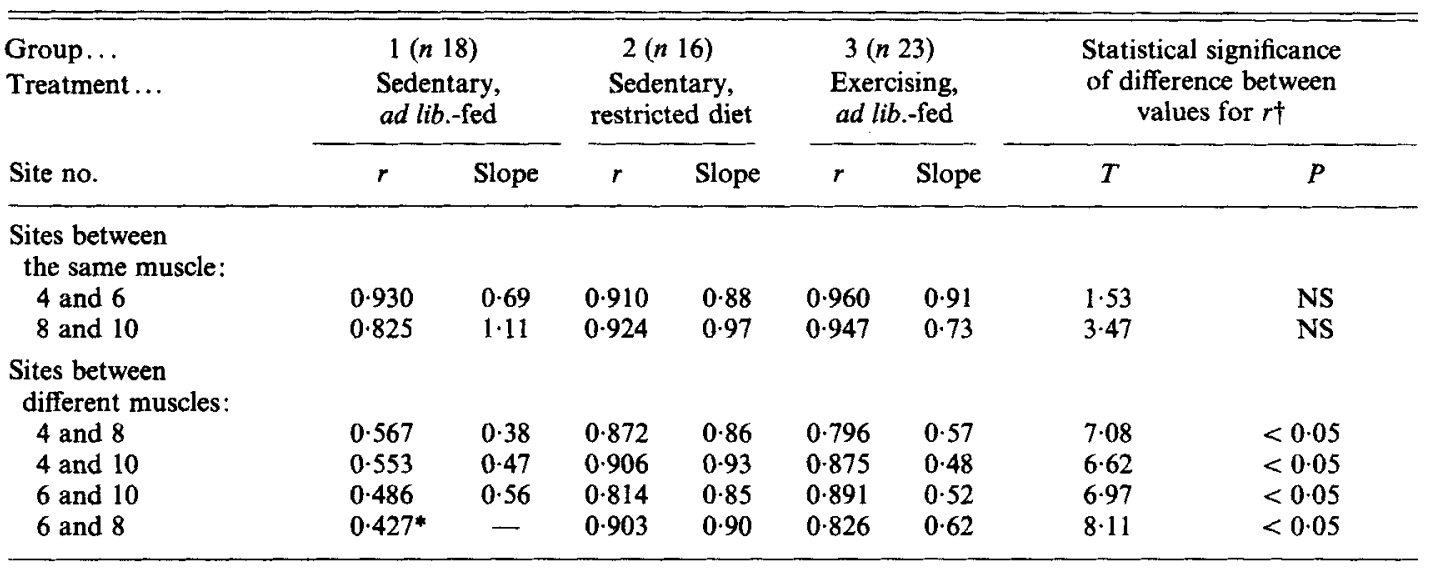

NS, not significant.

* Value was not significant $(P>0.05)$, thus no value for the slope has been given; all other values were significant $(P<0 \cdot 05)$.

$\dagger$ Fisher's $z$-transformation test; $T=\sum_{i=1}^{3}\left(n_{i}-3\right)\left(z_{i}-\bar{z}\right)^{2}$.

Table 4. Values for correlation coefficients relating volumes of adipocytes from sites at the edge and centre of the popliteal fat mass for guinea-pigs in the three treatment groups

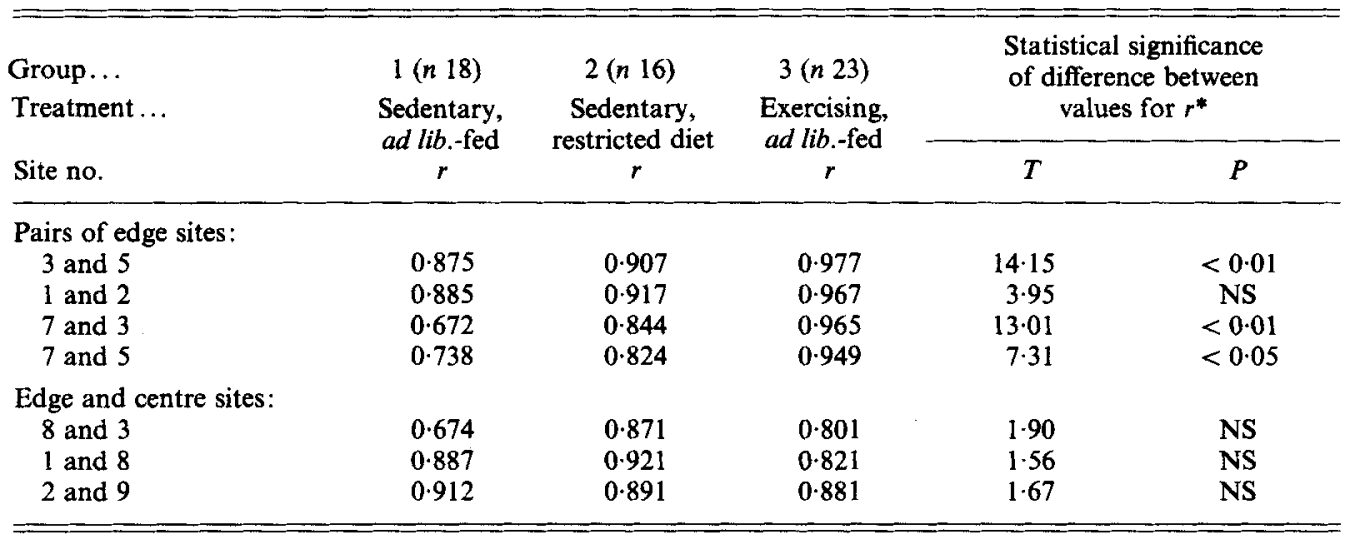

NS, not significant.

All values were significant $(P<0 \cdot 05)$.

* Fisher's $z$-transformation test; $T=\Sigma_{i=1}^{3}\left(n_{i}-3\right)\left(z_{i}-\bar{z}\right)^{2}$.

sites in GLS are summarized in Table 5. The correlations between the centre sites (GLS site 1 and POP site 8), edge sites away from fascia (GLS site 2 and POP site 1) and edge sites near fascia (GLS site 4 and POP site 2) were highly significant at $P<0.01$ in all three treatment groups, and there was no significant difference between the correlation coefficients for the different treatment groups. The only significant difference was in the relationship between the two samples from sites in narrow regions between muscles (GLS site 3 and POP site 4) but, even in this case, the exercising (group 3) animals and sedentary (group 
Table 5. Values for correlation coefficients relating volumes of adipocytes from comparable sites in the popliteal (POP) fat mass and the fat mass under the gluteus superficialis muscle (GLS) for guinea-pigs in the three treatment groups

\begin{tabular}{lccccc}
\hline $\begin{array}{l}\text { Group... } \\
\text { Treatment } \ldots\end{array}$ & $\begin{array}{c}1(n \text { 18) } \\
\text { Sedentary, } \\
\text { ad lib.-fed } \\
\text { Site no. }\end{array}$ & $\begin{array}{c}2(n \text { 16) } \\
\text { Sedentary, } \\
\text { restricted diet } \\
r\end{array}$ & $\begin{array}{c}3(n \text { 23) } \\
\text { Exercising, } \\
\text { ad lib.-fed }\end{array}$ & $\begin{array}{c}\text { Statistical significance } \\
\text { of difference between } \\
\text { values for } r \dagger\end{array}$ \\
\hline GLS 1 and POP 8 & 0.852 & 0.897 & 0.860 & 0.30 & $P$ \\
GLS 2 and POP 1 & 0.680 & 0.884 & 0.874 & 3.00 & NS \\
GLS 4 and POP 2 & 0.764 & 0.852 & 0.856 & 0.73 & NS \\
GLS 3 and POP 4 & $0.236^{*}$ & 0.868 & 0.841 & 10.88 & $<0.01$ \\
\hline
\end{tabular}

* Value was not significant $(P>0.05)$; all other values were significant $(P<0.05)$.

+ Fisher's $z$-transformation test; $T=\Sigma_{i=1}^{3}\left(n_{i}-3\right)\left(z_{i}-\bar{z}\right)^{2}$.

2) animals produced similar results. Thus the correlation between adipocytes volumes in anatomically distant sites is not significantly altered by exercise. These findings suggested that only adipocytes adjacent to, or lying between, synergistic muscles developed close similarity in volume following prolonged, gentle exercise (see Tables 3 and 4).

In both groups 1 and 2, no significant correlation could be demonstrated between the gross weight of the biceps femoris muscle and the volume of adipocytes in any of the eleven POP sites. However, in group 3 the $F$ values of the regression of adipocyte mean cell volumes of POP sites 1, 2, 3, 4, 5, 6 and 7 and the gross weight of the biceps femoris muscle all fell between 6.90 and 12.03 , indicating significant regression at $P<0.05$. In each case the regression between muscle weight and adipocyte volume was negative. None of the regressions between sites $8,9,10$ or 11 and the weight of the biceps femoris muscle were significant at $P<0.05$; but there was a negative correlation between the volume of adipocytes at POP site 11 and the weight of the semimembranosus-semitendinosus group of muscles, which was significant at $P<0.05$. In other words, the mass of a muscle group correlates with the volume of adipocytes immediately adjacent to it, but the dimensions of a muscle have no detectable relationship with the size of adipocytes distant from the muscle in question. This effect seems to require the muscles to be used frequently and strenuously, since it was not detected in animals confined to small cages whether their adipocytes were large (group 1) or small (group 2).

\section{DISCUSSION}

The aim of the present study was to test the hypothesis that local interactions between adipocytes and adjacent tissues play a part in the determination of adipocyte volume. Pond et al. (1984) found significantly higher correlations between the volume of adipocytes from non-homologous superficial and intra-abdominal sites in exercised and fasted guinea-pigs (groups 2 and 3) than in sedentary ad lib.-fed animals. Similar results were found in the present study, but the correlations were only significantly different between treatment groups when adipocyte samples from between or beside the same or synergistic muscles are compared (Tables 3, 4 and 5). This difference was not due to a greater similarity in the absolute size of the adipocytes in the group 3 animals than in the group 1 specimens, as the results in Table 2 show. Thus the effect of a modest level of exercise or regular, mild fasting seems to be to cause adipocytes of different mean volumes to correlate more closely. We conclude therefore that mechanical or biochemical events in the muscle, or some 
combination of mechanical and biochemical events, are playing a part in regulating the volume of adipocytes immediately adjacent to it.

Our experiments cannot exclude a biochemical explanation for these results; it is possible that a metabolite taken up or released by a muscle brings about the release or uptake of lipid in adjacent adipocytes, thus changing their volume. If the results described here were due to diffusion of a metabolite into or out of the muscle, adipocytes further away from the muscle would be less affected than those adjacent to it. However, the increased exercise performed by the group 3 animals was almost as effective in bringing about high correlations between the volumes of adipocytes deep in the centre of the POP adipose mass (Table 3) as it was in promoting higher correlations between the volumes of adipocytes close to the interface between muscle and adipose tissue (Table 4). An explanation involving diffusion of a metabolite also cannot account for the fact that increased exercise failed to bring about significant changes in the correlation between the volume of adipocytes at POP sites 6 and 8 , while substantially altering the relationship between the size of cells in POP sites 4 and 6 and POP sites 8 and 10 . We think, therefore, that the findings presented here are consistent with the suggestion that mechanical forces exerted by the muscle during contraction are playing a part in determining the volume of adjacent adipocytes, independent of the effect of such contraction on the over-all energy budget and hormone level of the animal as a whole.

Adipocytes which are repeatedly subjected to similar forces because they are situated beside or between synergistic muscles tend to correlate more closely than those which experience fewer or weaker forces, or which are subjected to difference forces due to being between different muscles. We suggest that these forces arise when muscle fibres change shape during contraction and that they are transmitted to the adipocytes via the fascia joining fat to muscle and the collagenous matrix component of the adipose tissue. If the effect were due to bulk squeezing of the adipose mass, without involving the collagenous matrix which permeates through the tissue, the consistent difference in mean volume, and poor correlation between the volumes of adipocytes from centre and edge samples of POP would not be expected. Direct measurements of the pressure inside small groups of adipocytes while adjacent muscles contract under artificial stimulation confirm this suggestion (C. M. Pond, unpublished results).

The high correlation between the volumes of intermuscular adipocytes in the group 2 animals may arise because the regular fasting, causing these and other adipocytes to undergo frequent changes in volume, may act synergistically with the forces produced by the adjacent muscles to bring about closer correlations. Results from groups 2 and 3 were significantly different in respect of the slope of the equations relating the centre sites between different muscles in POP (see Table 3). It is unlikely that this effect was due to the smaller number of adipocytes in the POP of group 2 animals (see Table 1); when fewer cells occupy the same space, one would expect each cell to be larger. However, group 3 animals had the full complement of adipocytes in POP and, in POP site 10, larger adipocytes than those in the equivalent site from group 2 animals (Student's $t$ test, $t 3 \cdot 12, P<0 \cdot 05$ ), the opposite result to that which would be expected (see Tables 1 and 2).

The suggestion we favour is that the differences in slope arise because the adipocytes experience different forces when they are situated between different pairs of muscles. The effects are most pronounced when the muscles are undergoing regular exercise. The findings from other mammalian species support this conclusion; POP site 10 was found to contain relatively-large adipocytes in all mammals studied, even though the gross weight of the POP fat mass ranged from $200 \mathrm{~g}$ in an adult lion to less than $0.3 \mathrm{~g}$ in the small rodent, Galea (Pond, 1984). This comparative information indicates that relatively large adipocytes appear at this anatomical site, regardless of its absolute dimensions. 


\section{CONCLUSIONS}

The findings presented here demonstrate a consistent pattern of arrangement of adipocytes of different relative volumes within a single intermuscular fat mass. The relationship between the volumes of cells at different sites can be modulated by mechanical activity of adjacent muscles. The effect is probably mechanical and may be mediated by the collagenous matrix which connects adipose tissue to adjacent muscles.

Equipment for this study was provided by a grant from the Open University Research Committee. The authors thank Dr P. Murphy for his help with the statistical analysis and computing methods.

\section{REFERENCES}

Butler-Hogg, B. W. \& Wood, J. D. (1982). Animal Production 35, 253-262.

Callow, E. H. (1950). Journal of Agricultural Science 40, 1-7.

Edgerton, V. R. (1978). American Zoologist 18, 113-125.

Garrow, J. S. (1978). Energy Balance and Obesity in Man, 2nd ed. Amsterdam: Elsevier-North-Holland.

Goss, R. J. (1978). The Physiology of Growth. London: Academic Press.

Kirtland, J. \& Gurr, M. I. (1979). International Journal of Obesity 3, 15-55.

Miller, M. E., Christensen, G. C. \& Evans, H. E. (1964). Anatomy of the Dog. Philadelphia: W. B. Saunders Co.

Moody, W. G. \& Cassens, R. G. (1968). Journal of Food and Science 33, 47-52.

Pond, C. M. (1984). In Sympositum of the Zoological Society of London 52, 1-31.

Pond, C. M., Mattacks, C. M. \& Sadler, D. (1984). British Journal of Nutrition 51, 415-424.

Sjöström, L. (1980). In Obesity, pp. 72-100 [A. J. Stunkard, editor]. Philadelphia: W. B. Saunders Co. 